\title{
REVIEW
}

\section{Using the Business Model Canvas to Guide Students in Building Business Plans}

\author{
David A. Holdford, PhD, Vasco M. Pontinha, MPharm, MA, Tyler D. Wagner, PharmD \\ Virginia Commonwealth University, School of Pharmacy, Richmond, Virginia
}

Corresponding Author: David A. Holdford, Virginia Commonwealth University, School of Pharmacy, 410 North 12th Str., Box 980581, Richmond, VA, 23298. Tel: 804-828-6103. Email: daholdfo@ vcu.edu

Submitted May 6, 2021; accepted July 26, 2021; ePublished August 2021

\begin{abstract}
Objective. To review the use of the business model canvas, a one-page visual description of a business initiative, as a tool for teaching pharmacy students about entrepreneurship and business planning in pharmacy practice settings.

Findings. Students often struggle to develop the mindset, skillset, and toolset to effectively apply business modeling and planning processes to pharmacy practice settings. Over years of experimentation and various iterations in a pharmacy practice management class, a new business model canvas was developed and refined. The canvas contains thirteen sections which emphasize key terms, concepts, and ideas crucial for achieving entrepreneurial competencies. Using the Zone of Proximal Development as a framework, the course structure offered a range of supportive activities that guided students to independent competence. The business model canvas formed a framework around which assigned course readings, exercises, and group assignments helped pharmacy students build confidence and competence in completing a capstone business plan assignment.

Summary. This paper provides recommendations and examples of how to structure a course in the Doctor of Pharmacy (PharmD) curricula using an entrepreneurial tool, the business model canvas, to help students master business competencies. Recommendations and lessons-learned are provided.

Keywords: entrepreneurship, curriculum development, course development, pharmacy management, community pharmacy
\end{abstract}

\section{INTRODUCTION}

The modern, practicing pharmacist must be prepared to meet many challenges on a daily basis. While some will be related to the clinical aspects of patient care and the management of patients with complex medical conditions, other significant challenges arise while managing pharmacy practice. Indeed, the failure of pharmacists to serve patients' needs is rarely the result of clinical matters such as not knowing the chemical structure of a drug or its pharmacokinetic profile. Rather, failure is more often the result of unsustainable business models and poor practice management.

This reality is why standards have been set in pharmacy education for achieving competencies in business and entrepreneurship. ${ }^{1,2}$ The Accreditation Council for Pharmacy Education (ACPE) considers business management competencies such as "the ability to develop a sound business plan for clinical service programs" as important for an entry level pharmacist. ${ }^{1}$ American Association of Colleges of Pharmacy CAPE Outcome 4.3 specifically relates to innovation and entrepreneurship associated with envisioning better ways of accomplishing professional goals. ${ }^{2}$

There are numerous strategies for achieving competencies in business management and entrepreneurship. These competences can be acquired through required didactic courses, ${ }^{3-8}$ electives,${ }^{9-11}$ co-curricular activities, ${ }^{12}$ workshops, ${ }^{13}$ experiential rotations, ${ }^{14}$ or a combination of strategies. Courses can focus on initiatives in ambulatory care, ${ }^{9}$ mass merchandise pharmacy, ${ }^{3}$ community pharmacy, ${ }^{6,10,15,16}$ clinical pharmacy, ${ }^{5,7}$ or students can have the freedom to choose from an array of business ideas. ${ }^{4,15}$ Competency is commonly demonstrated with the presentation of an innovative service, product, or program via a written business plan, an oral pitch of a business plan, or both.

The purpose of any business plan, including one in pharmacy practice, is to describe the business model of an initiative. A business model, in contrast to a business plan, is a general depiction of how a business or institution serves or intends to serve customers over time. ${ }^{17,18}$ All business initiatives have business models, although the model may not be summarized in a formal, detailed document like a business plan. Sometimes businesses do not have business plans because the process of crafting one can be time consuming and difficult. For other initiatives, a business plan is more detailed than necessary. Some have suggested replacing the business plan with a new instrument, the business model canvas, especially for innovative initiatives with high levels uncertainty about what business model to pursue. ${ }^{19}$

A business model canvas is a strategic management tool that provides a comprehensive framework for describing and understanding the crucial elements of any business enterprise, including innovative pharmacist services. ${ }^{20,21}$ It differs from 
a business plan, which is a more formal, detailed description of an initiative. Both describe the business model, but in varying levels of detail, with the canvas outlining the business model on a single page.

The business model canvas offers a process of exploration and analysis prior to writing a business plan. Entrepreneurs and intrapreneurs start by developing an initial canvas that goes through a series of drafts based upon conversations with customers and stakeholders, tests of the market, analyses of competitors and the organization behind the business model, assessments of the financials, and other tests of the model. This iterative process typically leads to a series of continually updated drafts that result in a final business model canvas. That canvas can then serve as an outline for a business plan which will be the final, comprehensive proposal. The analysis and thought used in drafting the business model canvas can result in a more thoughtful and detailed business plan.

This paper describes how the iterative process of building business models has been used in a course to teach pharmacy students how to write and present business plans for sustainable clinical pharmacy services. Students map their initial assumptions about a real life pharmacy initiative at the beginning of the semester, and each week they complete exercises that test their assumptions about the model. At the end of the semester, they use what they learn to complete a final business plan for a grade. Experiences and thoughts about choices made in designing the course are presented in this paper to help others interested in assisting students in learning how to develop sustainable innovations.

\section{Course Description}

The course "Community Pharmacy Practice Management II" is a required 2 credit hour course in the first semester of students' third year of pharmacy school at Virginia Commonwealth University. The course is taught simultaneously at three locations: in-person on the Richmond campus and virtually at the University of Virginia and INOVA campuses. The class size averages 100 students with approximately $70 \%$ of students being taught on the Richmond campus. The objective of the course is for students to develop the necessary competencies to design and manage pharmacist services in community pharmacy practice settings, although the course competencies are equally applicable to other practice settings including health systems and ambulatory care. Entrepreneurship competencies ${ }^{22}$ attained in the class include strategic planning, decision-making, creativity, innovation, divergent thinking, risk management, service design, practice management, communication, teamwork, and marketing.

Learning outcomes are achieved through assigned course readings, quizzes and tests of reading material, exercises to analyze and apply concepts from assigned readings, and group assignments associated with the development of a business plan. A flipped classroom approach to teaching is used where students are assigned readings or videos and quizzed prior to class. Class sessions accompany active learning exercises and provide an opportunity for live educator facilitation and feedback (Table 1). The flipped classroom approach allows students to work at their own speed and on their own time to learn content. Class time is used to master skills through group collaborative projects and discussions for the purpose of better and deeper learning. It provides the educator with more flexibility in adapting the material to the needs of students, with more class time spent on unscheduled topics or student questions. The professor's role in the class is primarily as a guide and a coach. Each week, the general structure of the class consists of before class, in class, and after class activities (Table 2).

The capstone of the course is a business plan project for an advanced practice pharmacy service or program. The overarching goal of the project is for students to develop the mindsets and skill sets to change pharmacy practice, one innovative project at a time. By the end of the course, the goal is to have students think like pharmacists whose careers and livelihoods depend on the success of their employers and practice setting.

The design and delivery of "Community Pharmacy Practice Management II" has evolved over the years through trialand-error. Earlier iterations of the course utilized a lecture-based format in which students submitted a completed business plan at the end of the semester. This format yielded business plans of uneven quality based upon assessments by faculty members and practicing pharmacists involved in the course. Some were quite good, meeting the standard of work expected of a professional (See Table 3). Others were disappointing, suffering from reoccurring problems that were summarized in a handout given annually to students titled, "The Most Common Problems to Avoid". This list included issues such as poorly written and vague descriptions of business plan elements, ignoring or inadequately addressing major sections of the plan (e.g., stakeholders), communicating in generalities instead of specifics, inconsistencies between sections of the plan including contradictory information and different fonts and writing styles, not getting out of the classroom to see the actual location where a program is to be offered, failing to find simple details that can be easily collected with a phone call or internet search (e.g., local competitors for the program, costs of radio, TV, newspaper ads), magical thinking in which students made unrealistic assumptions about how the world works (e.g., people will throw money at a poorly thought-out pharmacy idea), and boring the reader with a plan that is neither persuasive nor compelling. Sharing this list every semester helped students to avoid these problems and made them a less common occurrence. 
Other pharmacy educators identified similar challenges in teaching students about business. ${ }^{16,23}$ They highlighted the fact that most pharmacy students have little background or training in business which makes it more difficult to grasp basic terminology and concepts without significant remediation. Indeed, their understanding of pharmacy practice and life in general is also limited. Student inexperience frequently hinders appreciation of the need to learn the topic or the complexity of businesses centered on patient care. Teaching the topic is further complicated when it is not adequately integrated with other parts of the curriculum [e.g., advanced pharmacy practice experiences (APPEs)] and when class size makes it difficult for faculty to provide extensive personal feedback. Consequently, a significant gap must be traversed by faculty members tasked with teaching business and entrepreneurship.

\section{Zone Of Proximal Development}

The gap between what students know and what they need to know is called the zone of proximal development. ${ }^{24}$ Vygotsky's Zone of Proximal Development (ZPD) framework describes an educator's role in teaching topics that a student is unable to learn without assistance. According to Vygotsky, individuals acquire new knowledge and skills either on their own or through the assistance of others. Learning without help is sufficient for some things, but for more complex tasks and topics, individuals need help to traverse the ZPD. According to the ZPD framework, the educator's role is to guide learners as they move through the zone of proximal development by providing supportive activities, also known as scaffolding, with the goal of achieving independent competence.

The ZPD emphasizes three key components which aid the learning process. ${ }^{24}$ The first is an educator or guide whose knowledge and skills exceed that of the learner. The educator does not need to be an expert - just more knowledgeable than the learner. The second component is for opportunities be built into the process that allow interactions between people. Interactions can be with the professor, teaching assistants, outside mentors, and peers. These interactions provide opportunities for active learning by students. The final key component in the ZPD framework is the provision of scaffolding, or supportive activities, to aid the student through the zone to competency. Scaffolding consists of the various pedagogy provided by the educator to facilitate learning.

The ZPD framework was used in "Community Pharmacy Practice Management II" to guide students to develop their business plans. The task of competing a business plan fits the framework because it is an assignment that students cannot do on their own without assistance, yet it is not too difficult to complete given the right amount and type of guidance. Opportunities for interaction between people were built into the learning process through class assignments that encouraged conversations between peers. Other opportunities built into the course design included the assignment of a practice faculty mentor to answer questions about real-life pharmacy practice and hold periodic team conferences to talk through issues and problems. To help students achieve competency by working through the ZPD framework, they were guided using the business model canvas, thoughtfully selected real-life innovations around which students could build business models, and in-class exercises, all of which are described in the following section.

\section{Business Model Canvas}

The business model canvas is a tool to help entrepreneurs understand a business model in a concise and organized way. ${ }^{20}$ It presents the structure of a business plan on single page, allowing individuals a quick overview of its key components, thereby facilitating a quick grasp of any business initiative. The canvas can be used to accelerate the development and testing of business ideas before they reach the stage of a formal business plan. Class exercises for students can be built around the elements of the plan. The original business model canvas was developed by Osterwalder ${ }^{20}$ and consists of nine building blocks.

1. Customer segments

2. Value proposition

3. Revenue streams

4. Channels

5. Customer relationships

6. Key activities

7. Key resources

8. Key partners

9. Cost structure

A variation of Osterwalder's canvas was developed for this course over time for the purpose of teaching pharmacy students (Figure 1). Although Osterwalder's model is a widely adopted framework, experience in teaching pharmacy students revealed that many had difficulty understanding fundamental ideas relating to building a business plan. Over years of experimentation and various iterations, the number of business building blocks was increased to thirteen to better emphasize key learning objectives and to address ideas that students struggled to grasp. The new business model canvas 
for pharmacists was also developed to match the major sections of the assigned written business plan, allowing it to be used as a scaffold to complete the plan.

The components of the business model canvas for pharmacy differ significantly from those in Osterwalder's canvas. Only four components were similar between the two; value proposition, revenues, costs, and stakeholders (key partners). All other components of Osterwalder's canvas were either replaced by new sections on the canvas (strengths and weaknesses, opportunities and threats, organization's operation, and implementation) or were modifications of Osterwalder's components (primary and secondary customers, service/product, communication plan, key activities, key resources, and channels). Despite their differences, both canvases cover all major elements of business models. The distinctions exist primarily in how the elements are named and presented to students.

The business model canvas for pharmacy has the following notable features. It contains all the elements of a business model in a one-page summary, which allows for a quick understanding of the plan's business model at a glance. The canvas presents the building blocks of a business in separate boxes, which ensures that no building blocks are ignored or insufficiently considered. The value proposition is placed at the center of the model to highlight the fact that all elements of the business revolve around the value delivered to customers. Use of the canvas mimics the scientific process by providing a well-structured process for testing the assumptions or hypotheses of a business model. It follows a problembased approach to building business models with each discrete element consisting of a problem to be solved (e.g., Who is our customer? What is our value proposition to the customer?). Finally, it encourages continuous iterations of the business model through customer interviews, prototyping, and small pilot tests based upon the assumption that the development of sustainable business ideas is a non-linear process.

In "Community Pharmacy Practice Management II", each business model canvas developed by students evolves over the semester through a series of group exercises that test initial drafts of the canvas and while clarifying details about the business idea (Table 4). The exercises allow students to build their plans in stages with numerous opportunities for experimentation and educator feedback. Ideas are played with and refined in preparation for the final formal business plan document.

\section{Selection Of Business Ideas}

A critical decision in the success of a business model project is the choice of a project. Projects can be (a) assigned by the professor, (b) generated by students, (c) solicited from local pharmacists, or (d) part of an established contest like the National Community Pharmacist Association (NCPA) business plan competition. Business ideas can be real (i.e., intending to solve an actual business problem) or a simulation (i.e., based upon a made-up scenario). The choice requires balancing projects that are interesting to students, challenging but not too challenging, realistic but not without some structure, achievable given the students' often limited knowledge and experience, and not too time-intensive for the professor.

Allowing students to come up with their own idea helps them develop the important skills of idea generation, but it can lead to several problems. For many, this task falls into the Zone of Proximal Development and requires a lot of assistance from faculty members. Without significant help, students tend to default to their limited personal and professional experiences and often generate trivial ideas (e.g., a new pill counting tray), minor improvements in convenience (e.g., an additional pharmacy drive-thru window), or innovations outside of the pharmacy profession (e.g., combination health food store and gym). Others suggest complex technology solutions that exceed their expertise to build and implement (e.g., Siri-like voice-controlled personal assistant for medication adherence) causing them to be quickly overwhelmed and frustrated. Indecision grips other students leading to procrastination or not offering any ideas at all.

For projects in which there is a short timeline between the generation of an idea and the deadline for submitting a business plan, it is important for students to start with an established idea early in the semester. In "Community Pharmacy Practice Management II," students are provided with a structured choice in which they can choose from a list of business ideas which are generated by faculty members who also offer to act as mentors. Students are given an alternative option to propose their own ideas to be vetted by the professor, but this option has never been selected. This structured choice method of identifying projects avoids the problem of students getting too far into the semester without a viable business plan idea, and it provides an opportunity for advanced practice faculty members to tackle, real-life problems faced in practice. Example projects completed in the course include pharmacogenetic testing services at a local independent pharmacy, expansion of medical center services to local college students, creation of a financially sustainable position for a pharmacist within a local physician practice, drive-thru INR monitoring, CKD screening in a local community pharmacy, retinal screening service for underserved patients with diabetes, home blood pressure monitoring at a clinic for underserved patients, telemedicine in a family medicine practice with a collaborative practice agreement, a new faculty oncology clinic, a student-led flu immunization initiative, and contract tracing services for businesses and government entities. 
Proponents of the business model canvas recommend developing an initial draft of the entire canvas instead of building it piece-by-piece. ${ }^{19,20}$ The purpose is to describe an initial, big picture view of the business model which will go through numerous drafts. The initial draft is seen as a series of hypotheses about the business model that need to be tested. For example, the primary customer for a diabetes management program might be hypothesized to be individuals from underserved communities with type II diabetes, but conversations with patients, payers, and providers might result in a new hypothesis that the primary customers are prescribing physicians.

The initial draft of the business model canvas of the proposed patient care service should be completed early in the semester because class activities will revolve around testing and improving the initial canvas. Over the course of the semester, exercises for each element of the canvas will be completed, allowing students to reconsider their hypothesized business models and pivot to other hypotheses as needed.

\section{Class Exercises}

The actual learning from the course occurs when students test their hypotheses with in-class exercises. These exercises help students deeply consider their initial ideas for the model. The exercises also require students to provide more details for each element of the canvas, which can be used later in the final business plan. Table 4 lists the class exercises used by student groups to build their final business plan.

Using the business model canvas and class exercises throughout the semester makes the final writing of the business plan much easier. Rather than franticly writing the plan at the last minute, students compile what they learned from the exercises and edit these findings into a document. Students are provided with the rubric shown in Table 3 and examples of business plans from previous years to further communicate what is expected of them. Students adopt some ideas from previous year's plans and add their own personal touches, typically resulting in incremental improvements in plans from year-to-year. This has made grading the plans more enjoyable because good plans are a pleasure to read. Although some groups still submit disappointing work, the level of disappointment has diminished in comparison to past years. The overall quality of submissions is such that students are encouraged to list the completed business plans on their resume so potential employers are aware of this accomplishment.

\section{CONCLUSION}

The pharmacy business model canvas in this paper has been built through trial and error using ideas from the business literature. Most of the ideas and techniques described above have been tested and promoted by experienced entrepreneurs who recommend an experiential approach to teaching and continuous qualitative feedback throughout the process. ${ }^{19,20} \mathrm{~A}$ similar approach was described in this paper where assessment of business plans was limited to qualitative assessments by the authors using the rubric provided in Appendix A. Therefore, recommendations about the course design, tools, and delivery are not supported by data-driven evidence (e.g. plan scoring comparisons) and should be viewed with caution. In the future, research should attempt to validate the rubric used to evaluate plans to allow quantitative assessment of the recommendations described in this paper. Still, the recommendations in this paper may be useful to pharmacy educators who are considering other approaches to teaching about business and business planning.

The pharmacy business model canvas can form a portion of the scaffolding needed for pharmacy students to cross the Zone of Proximal Development to independent competency. All tasks within the business plan can be completed at a high level by students with appropriate assistance. When provided with the right ideas, directions, guidance, and feedback, students can generate professional work. Experience with the use of the business model canvas and accompanying in-class exercises show that students can complete professional business plans designed to solve real-world problems in clinical practice. By the end of the semester, students have the skillset to submit business plans that they would be proud to show a potential employer.

\section{REFERENCES}

1. PharmD Program Accreditation - Accreditation Council for Pharmacy Education. https://www.acpeaccredit.org/pharmd-program-accreditation/. Accessed April 12, 2021.

2. Medina M, Plaza C, Stowe C. Center for the Advancement of Pharmacy Education (CAPE) educational outcomes 2013. Am J Pharm Educ. 77(8):162.

3. Morris Moultry A. A Mass Merchandiser's Role in Enhancing Pharmacy Students' Business Plan Development Skills for Medication Therapy Management Services. Am J Pharm Educ. 2011;75(7):133. doi:10.5688/ajpe757133

4. Gatwood J, Hohmeier K, Farr G, Eckel S. A comparison of approaches to student pharmacist business planning in pharmacy practice management. Am J Pharm Educ. 2018;82(5):401-409. doi:10.5688/ajpe6279 
5. Skomo ML, Kamal KM, Berdine HJ. A required course in the development, implementation, and evaluation of clinical pharmacy services. Am J Pharm Educ. 2008;72(5). doi:10.5688/aj7205109

6. Perepelkin J. Redesign of a required undergraduate pharmacy management course to improve student engagement and concept retention. In: American Journal of Pharmaceutical Education. Vol 76. American Association of Colleges of Pharmacy; 2012. doi:10.5688/ajpe7610201

7. Hicks C, Siganga W, Shah B. Enhancing pharmacy student business management skills by collaborating with pharmacy managers to implement pharmaceutical care services. Am J Pharm Educ. 68(4):94.

8. Shahiwala A. Entrepreneurship skills development through project-based activity in Bachelor of Pharmacy program. Curr Pharm Teach Learn. 2017;9(4):698-706. doi:10.1016/j.cpt1.2017.03.017

9. Wilhoite J, Skelley JW, Baker A, Traxler K, Triboletti J. Students' perceptions on a business plan assignment for an ambulatory care pharmacy elective. Am J Pharm Educ. 2019;83(5):892-898. doi:10.5688/ajpe6789

10. Bullock KC, Horne S. A didactic community pharmacy course to improve pharmacy students' clinical skills and business management knowledge. Am J Pharm Educ. 2019;83(3):347-355. doi:10.5688/ajpe6581

11. Slavcev RA, Waite NM, Jennings B. Shaping pharmacy students' business and management aptitude and attitude. Curr Pharm Teach Learn. 2016;8(5):672-680. doi:10.1016/j.cpt1.2016.06.003

12. Mogul A, Laughlin E, Lynch S. A co-curricular activity to introduce pharmacy students to the concepts of innovation and entrepreneurship. Am J Pharm Educ. 2020;84(8):1077-1084. doi:10.5688/ajpe7805

13. Laverty G, Hanna LA, Haughey S, Hughes C. Developing entrepreneurial skills in pharmacy students. Am J Pharm Educ. 2015;79(7). doi:10.5688/ajpe797106

14. Timsina S, K C B, Adhikari D, Alrasheedy AA, Mohamed Ibrahim MI, Kaundinnyayana A. A new experimental community pharmacy internship module for undergraduate pharmacy students in western Nepal: overview and reflections. J Educ Eval Health Prof. 2017;14:18. doi:10.3352/jeehp.2017.14.18

15. Good Neighbor Pharmacy NCPA Pruitt-Schutte Student Business Plan Competition | NCPA. https://ncpa.org/business-plan-competition. Accessed April 22, 2021.

16. Singleton JA, Nissen L. Teaching Pharmacy students how to manage effectively in a highly competitive environment. Pharm Educ. 2014;14(1):21-25.

http://pharmacyeducation.fip.org/pharmacyeducation/article/download/184/158. Accessed April 22, 2021.

17. Teece DJ. Business models, business strategy and innovation. Long Range Plann. 2010;43(2-3):172-194. doi:10.1016/j.lrp.2009.07.003

18. Holdford DA. Understanding business models in pharmacy schools. Am J Pharm Educ. 2017;81(5). doi:10.5688/ajpe81582

19. Blank S. Why the Lean Start-Up Changes Everything. Harv Bus Rev. 2013;91(5):63-72. https://hbr.org/2013/05/why-the-lean-start-up-changes-everything. Accessed April 20, 2021.

20. Osterwalder A, Pigneur Y. Business Model Generation: A Handbook for Visionaries, Game Changers, and Challengers | Wiley. New York, NY: Wiley; 2010. https://www.wiley.com/enus/Business+Model+Generation\%3A+A+Handbook+for+Visionaries $\% 2 \mathrm{C}+\mathrm{Game}+\mathrm{Changers} \% 2 \mathrm{C}+$ and $+\mathrm{Challenge}$ rs-p-9780470876411. Accessed April 12, 2021.

21. Pontinha VM, Wagner TD, Holdford DA. Point-of-care testing in pharmacies-An evaluation of the service from the lens of resource-based theory of competitive advantage. J Am Pharm Assoc. 2021;61(2):e45-e54. doi:10.1016/j.japh.2020.11.005

22. Mattingly TJ, Mullins D, Melendez DR, Boyden K, Eddington ND. A systematic review of entrepreneurship in pharmacy practice and education. Am J Pharm Educ. 2019;83(3):273-280. doi:10.5688/ajpe7233

23. Latif DA. A management skills course for pharmacy students. Am J Pharm Educ. 2004;68(1):1-10. doi:10.5688/aj680103

24. Wass R, Golding C. Sharpening a tool for teaching: The zone of proximal development. Teach High Educ. 2014;19(6):671-684. doi:10.1080/13562517.2014.901958 
Learning principles of pharmacy practice management

Practicing the principles on real life problems
Assigned readings, assessment of assigned readings

Teams work together on:

- Business model canvas

- Business plan
Mini-lectures, class discussions, guest lectures

Assigned exercises 
Table 2. Typical Student Activities for Each Topic (50 min class)

\begin{tabular}{cccccccc}
\hline $\begin{array}{c}\text { Student } \\
\text { activities }\end{array}$ & $\begin{array}{c}\text { Read } \\
\text { Assignment }\end{array}$ & $\begin{array}{c}\text { Take quiz over } \\
\text { reading } \\
\text { (comprehension) }\end{array}$ & $\begin{array}{c}\text { Engage with } \\
\text { mini-lecture }\end{array}$ & $\begin{array}{c}\text { Breakout into } \\
\text { groups for } \\
\text { exercise }\end{array}$ & $\begin{array}{c}\text { Discuss } \\
\text { exercise in } \\
\text { class }\end{array}$ & $\begin{array}{c}\text { Insert } \\
\text { exercise } \\
\text { into } \\
\text { business } \\
\text { model }\end{array}$ & $\begin{array}{c}\text { Discuss } \\
\text { changes in } \\
\text { business model }\end{array}$ \\
Time & $<30$ min. & $<10$ min. & 10 min. & 30 min. & 10 min. & 1 min. & Variable \\
Touchpoint & $\begin{array}{c}\text { Asynchronous } \\
\text { online course } \\
\text { management } \\
\text { platform }\end{array}$ & $\begin{array}{c}\text { Asynchronous } \\
\text { online course } \\
\text { management } \\
\text { platform }\end{array}$ & $\begin{array}{c}\text { Synchronous } \\
\text { in-person or } \\
\text { via video } \\
\text { conference }\end{array}$ & $\begin{array}{c}\text { Synchronous } \\
\text { in-person or } \\
\text { video } \\
\text { conference } \\
\text { breakout }\end{array}$ & $\begin{array}{c}\text { Synchronous } \\
\text { in-person or } \\
\text { via video } \\
\text { conference }\end{array}$ & $\begin{array}{c}\text { Shared } \\
\text { processing } \\
\text { program }\end{array}$ & $\begin{array}{c}\text { Synchronous } \\
\text { in-person or via } \\
\text { video } \\
\text { conference }\end{array}$ \\
\hline
\end{tabular}

Note: In this class the online course management program was Canvas, the video conference software was Zoom, and the shared word processing program was Google Docs. 


\section{Not up to expectations}

$\begin{array}{ll}\text { Executive } & \text { Executive summary does } \\ \text { Summary } & \text { not present a clear } \\ & \text { overview of the plan; } \\ & \text { main points are not } \\ & \text { outlined or not clear }\end{array}$

\section{Description of Service/ product}

Value

Proposition

Organization's Operation

SWOT Analysis
Plan is missing a

description of the service/ product or the description is vague or inadequately developed; few if any details are provided. No visual illustrations provided.

Plan does not make a clear and/or compelling case for why customers should use the service/ product; benefits and impact on customer needs are not clearly presented

Plan is missing a business description, or description of the business is vague and inadequately developed; few if any details are provided regarding product/service offered and strategic elements; business model is not sufficiently described; does not clearly describe the benefits of the good/service offered and how it addresses consumer needs; overall company focus is unclear SWOT analysis is not provided, is inadequate, or is incomplete in significant respects; analysis is superficial, few if any competitive advantages are identified

\section{Level expected of a team of good students completing an academic exercise}

\section{Executive summary} provides a satisfactory overview of the plan; summary is missing a few minor points but meets expectations

The service/ product idea is clearly presented; with a few minor omissions, acceptable visual presentation if appropriate, provides support for the design using appropriate citations. Visual illustrations provided.

Value proposition is clearly presented; with a few minor omissions, benefits and impact on customer needs are clearly presented although some reasons may need further development, but meets minimum standards

The business idea is clearly presented; strategic elements are satisfactorily outlined; with a few minor omissions, the business plan describes the reasons for starting the business, product or service offered, and the business model; the company's value proposition is described, but is less than fully developed; business description is lacking some detail, but meets minimum standards

\section{SWOT analysis describes} major strengths, weaknesses, opportunities, and threats, but analysis is limited or missing a few elements; analysis identifies competitive advantages, but

\section{Level expected of a pharmacist who is trying to change the practice of pharmacy, quality and presentation is very professional}

Executive summary is clear, concise, and effective; summary provides a thorough overview of the plan and fully outlines and describes main points Presents the service/ product idea thoroughly and effectively; uses detailed visual presentation if appropriate, provides support for the design using appropriate citations. Good visuals provided.

Value proposition is presented in a clear and compelling way; benefits and impact on customer needs are clear and supported by proof points

Presents the business idea thoroughly and effectively, including the company's mission, vision, goals, objectives, and overall strategic direction; fully outlines the reasons for launching the venture, and describes product/service offered, company focus, and business model; clearly and convincingly articulates the company's distinctive value proposition

SWOT analysis describes major strengths, weaknesses, opportunities, and threats, analysis is detailed and insightful; analysis identifies competitive advantages and
0 to 5

Points

0 to 
a discussion of the impact on market success is missing or less than fully developed discusses the impact on market success
Primary and secondary customers

\section{Partners and Competitors}

Costs

Revenues

Marketing
Communications
Plan

Implementation
The primary and secondary customers are not identified, differentiated, and/or described; customers' needs to be served by the service/ product are not clear. No customer persona is presented

Key partners and competitors are not identified, differentiated, and/or described; details about their potential impact on success of the service/ product are not explained or vague

Costs are not adequately identified, differentiated, and/or described; necessary cost documents are missing, inadequate, or incorrect

Sources of revenue are not adequately described or insufficient to sustain the service/ product over time, documents are missing, inadequate, or incorrect

The objective of the plan is missing or not clear; the message and strategy are vague or confusing, the communication mix is not integrated, no measure for success is presented

Implementation of the plan is not provided, inadequate, not fully developed, or incomplete; description of major issues is missing or lacking detail; no plan is
The primary and secondary customers are identified, differentiated, and/or described; some details are missing or vague, customers' needs to be served by the service/ product are described. A customer persona is presented but in superficial detail.

Key partners and competitors are identified, differentiated, and/or described; some details are missing or vague, their potential impact on success of the service/ product is explained or vague but needs greater insight Costs are adequately identified, differentiated, and/or described with only minor errors; necessary cost documents are present with only some errors

Sources of revenue are described but lack of detail makes it unclear that they will be sufficient to sustain the service/ product over time, documents are presented with only minor errors

The objective of the plan is present and clear; the message and strategy are acceptable but does not use best practice from the textbook, the communication mix is integrated, a measure for success is presented Implementation of the plan is provided and only missing some details, some issue overlooked but what is presented is minimally acceptable
The primary and secondary customers are identified, differentiated, and/or described; details are clear and complete, customers' needs to be served by the 0 to service/ product are described. Customer persona is presented and detailed

Key partners and competitors are identified, differentiated, and/or described; specific details are provided, specific individuals are contacted and their insights about the plan are presented

Costs are adequately identified, differentiated, and/or described with no errors; necessary cost documents are present with no errors

Sources of revenue are described and detailed, a case is made for financial sustainability, documents are presented with only minor errors

The objective of the plan is present and clear; the message and strategy uses best practices and the mix is integrated, a measure for success is presented

Implementation of the plan is detailed and complete without need for further explanation

0 to 5 
presented for assessing success
Well written and easy to read; no misspellings or grammar errors; quality of presentation is acceptable but not what is expected of a professional.
Presents a clear overview of the business plan; is well written and easy to read; no misspellings or grammar errors

\section{Total Possible Points}


Business Model Building Description of class exercise Block

Organization's Operation Students complete a description of the organization behind the pharmacy enterprise

Strengths/ Weaknesses Opportunities/ Threats

Service/ Product

Value Proposition

Primary Customers/ Secondary Customers

Competitors

Partners

Costs

Revenues and other benefits

Communication Plan

Implementation
Students conduct a SWOT analysis of their innovation

Students describe the innovation being offered to customers

Students develop a service blueprint about the service or program being offered

Students explain why the value to be delivered by an innovation differentiates it from competing options

Students build customer personas for key customer groups

Students complete a perceptual map of an innovation and a competitor analysis table

Students develop a stakeholder map and a power/interest matrix

Students fill in the revenue portion of the pro forma income statement for the business initiative

Students fill in the revenue portion of the pro forma income statement for the business initiative and complete a break-even analysis Students craft the messaging for an integrated marketing communications plan for a target audience

Students develop key elements of a marketing communications plan including touchpoints, channels, and budget

Students identify the most likely causes for an initiative's failure in the future and describe strategies for ensuring that they do not happen Students identify KPIs to evaluate the success of an initiative after implementation
Learning objective of the exercise

Consider the consistency of an innovation

with the mission, values, product

portfolio, and resources of the

organization

Investigate the relative competitive advantage of the initiative within identified markets

Provide a detailed but brief description of the innovation and its main features

Visually map out and explain the touchpoints between the customer and service providers

Write a compelling and clear statement about how the proposed innovation is better than any other choice available to customers

Prioritize customers and learn to visualize customer groups as individuals instead of generic groups Identify how competitors' offerings differ from the proposed innovation

Recognize various stakeholders and identify strategies for managing them

Identify all startup and ongoing operations costs for an initiative

Identify all potential sources of revenue generated by an initiative and the point at which revenues exceed costs Develop precise messaging that can be used across different channels and audiences

Apply a step-by-step process for developing a communications plan

Learn to realistically assess potential flaws in a business plan

Be able to define and measure success of an initiative

SWOT - Strength, Weakness, Opportunities, Threats; KPIs - Key Performance Indicators 
Figure 1. Business Model Canvas for Pharmacy

\begin{tabular}{|c|c|c|c|c|c|}
\hline \multirow{4}{*}{$\begin{array}{l}\text { Organization's } \\
\text { Operation - } \\
\text { Specific } \\
\text { background about } \\
\text { the organization } \\
\text { where the } \\
\text { product/service } \\
\text { will be provided }\end{array}$} & \multirow{2}{*}{$\begin{array}{c}\text { Strengths, } \\
\text { Weaknesses - } \\
\text { Your } \\
\text { organization's } \\
\text { capabilities to } \\
\text { serve targeted } \\
\text { customers } \\
\end{array}$} & \multicolumn{2}{|c|}{$\begin{array}{l}\text { Service/ Product } \\
\text { - What you are } \\
\text { offering }\end{array}$} & \multirow{4}{*}{$\begin{array}{l}\text { Secondary } \\
\text { Customers - } \\
\text { All other people } \\
\text { you may serve }\end{array}$} & \multirow{2}{*}{$\begin{array}{c}\text { Partners - } \\
\text { People or } \\
\text { businesses who } \\
\text { can help you } \\
\text { serve customers }\end{array}$} \\
\hline & & \multirow{2}{*}{\multicolumn{2}{|c|}{$\begin{array}{c}\text { Value } \\
\text { Proposition - } \\
\text { The case you } \\
\text { make to } \\
\text { customers }\end{array}$}} & & \\
\hline & \multirow{2}{*}{$\begin{array}{c}\text { Opportunities, } \\
\text { Threats - } \\
\text { Potential for } \\
\text { success or } \\
\text { failure in the } \\
\text { market }\end{array}$} & & & & Competitors - \\
\hline & & \multicolumn{2}{|c|}{$\begin{array}{c}\text { Primary } \\
\text { Customers - } \\
\text { People or } \\
\text { businesses you } \\
\text { want to serve } \\
\end{array}$} & & $\begin{array}{l}\text { businesses who } \\
\text { compete for your } \\
\text { customers }\end{array}$ \\
\hline $\begin{array}{l}\text { Costs - Financial } \\
\text { and nonfinancial } \\
\text { inputs needed to } \\
\text { serve customers }\end{array}$ & \multicolumn{2}{|c|}{$\begin{array}{l}\text { Revenue and other } \\
\text { benefits - Financial } \\
\text { and nonfinancial } \\
\text { outputs that sustain } \\
\text { your value proposition }\end{array}$} & \multicolumn{3}{|c|}{$\begin{array}{c}\text { Communication Plan - How your value } \\
\text { proposition is communicated to customers and } \\
\text { partners }\end{array}$} \\
\hline \multicolumn{6}{|c|}{ Implementation - Details about critical factors for success of business } \\
\hline
\end{tabular}

Adapted from Business Model Canvas by Osterwalder and Pigneur ${ }^{20}$ 